Magnac-sur-Touvre - Les Grands Champs de la Vallade

\title{
Catherine Roncier
}

\section{(2) OpenEdition Journals}

Édition électronique

URL : http://journals.openedition.org/adlfi/669

ISSN : 2114-0502

Éditeur

Ministère de la culture

Référence électronique

Catherine Roncier, « Magnac-sur-Touvre - Les Grands Champs de la Vallade », ADLFI. Archéologie de la France - Informations [En ligne], Poitou-Charentes, mis en ligne le 01 mars 2008, consulté le 01 mai 2019. URL : http://journals.openedition.org/adlfi/669

Ce document a été généré automatiquement le 1 mai 2019.

(C) Ministère de la Culture et de la Communication, CNRS 


\title{
Magnac-sur-Touvre - Les Grands Champs de la Vallade
}

\author{
Catherine Roncier
}

\author{
Identifiant de l'opération archéologique : 204647 \\ Date de l'opération : 2008 (EX) \\ Inventeur(s) : Roncier Catherine (INRAP)
}

Un projet de lotissement au lieu-dit « Les Grands Champs de la Vallade » à Magnac-surTouvre a donné lieu à la réalisation d'un diagnostic archéologique entre le 10 et le 18 mars 2008. Situé à l'est de l'agglomération d'Angoulême, le secteur concerné est caractérisé par de nombreux indices de sites mentionnés par la carte archéologique, en particulier mésolithiques et protohistoriques, et qui ont motivé la prescription du SRA.

A un kilomètre des sources de la Touvre, le terrain des Grands Champs de la Vallade se trouve en rive sud de cet affluent de la Charente. Il occupe le versant ouest d'un petit vallon creusé par le ruisseau de Bellevue qui s'écoule à quelques dizaines de mètre de l'angle nord-ouest de l'emprise. Ce petit ruisseau à l'écoulement intermittent prend sa source au pied du plateau d'Antournac et rejoint la Touvre à quelques centaines de mètre de ses sources.

D'après la carte géologique, le substrat se compose de formation du Crétacé, et notamment du Cénomanien moyen constitué de calcaire dans la partie sud, et du Cénomanien inférieur caractérisé par des sables et grès dans la zone basse au nord. Les observations recueillies sur le terrain ont permis d'identifier une zone caractérisée par un substrat argileux sableux jaune qui s'intercale entre les deux faciès dominants. Du fait de la nature du substrat, ce secteur se révèle particulièrement humide.

Les cinquante-cinq tranchées et fenêtres réalisées correspondent à une superficie de $2434,11 \mathrm{~m}^{2}$. Elles ont permis de sonder $6,80 \%$ de la superficie disponible, ce qui représente une reconnaissance satisfaisante de la parcelle. 
Les données archéologiques recueillies sur l'opération des Grands Champs de la Vallade sont minces. Dix sondages positifs ont livré 42 structures mais réparties de manière inégale sur l'ensemble du terrain. Le sondage 52 comprend à lui seul 31 structures, tandis que 11 autres structures prennent place dans 9 sondages différents.

La zone sud s'est avérée totalement vierge de tout vestige. Dans la moitié nord de la parcelle (sondages $33,37,45,47,48,51$ et 52), un réseau de drains contemporains permet d'assainir une zone humide en facilitant l'écoulement vers le ruisseau de Bellevue.

La tranchée 52 et son extension ont livré un ensemble de structures relativement dense. Il s'agit d'une fosse peu profonde et circulaire $(0,60 \mathrm{~m}$ de diamètre) et de 30 trous de poteaux circulaires d'un diamètre moyen de $0,20 \mathrm{~m}$ et dont la profondeur n'excède pas $0,20 \mathrm{~m}$. Si aucun plan de bâtiment ne semble se dessiner, certains alignements peuvent être soulignés et suggèrent l'installation à une époque indéterminée de structures légères de type clôture. Ils témoignent d'une fréquentation humaine, mais aucune organisation spatiale véritablement cohérente n'est apparue et aucun mobilier n'a été découvert permettant de la dater.

Le seul mobilier archéologique découvert est un tesson de céramique probablement de l'époque protohistorique. Il est associé dans le sondage 20 à un fossé interrompu de $9 \mathrm{~m}$ de long sur 0,60 m de large dont le comblement limoneux brun contient des cailloux calcaire. Sa fonction reste indéterminée.

Malgré les nombreuses données recueillies par la base Patriarche et qui ont motivé l'intervention, le diagnostic sur "Les Grands Champs de la Vallade » s'est globalement révélé négatif. Les vestiges archéologiques reconnus comprennent des structures en creux (trous de poteau, fossé, drains) dont l'état de conservation se révèle médiocre. Leur répartition est inégale sur l'ensemble du terrain et le mobilier demeure quasi absent. L'opération n'a pas permis de mettre au jour une occupation caractérisée.

RONCIER Catherine

INDEX

operation Expertise (EX)

Index chronologique : ép. contemporaine, Protohistoire

Index géographique : Poitou-Charentes, Charente (16), Magnac-sur-Touvre

Thèmes : argile, céramique protohistorique, drain, fosse, fossé, occupation du sol, trou de poteau, zone humide

\section{AUTEURS}

CATHERINE RONCIER

INRAP 